\title{
New Product Development in an Emerging Economy: Analysing the Role of Supplier Involvement Practices by Using Bayesian Markov Chain Monte Carlo Technique
}

\author{
Kanagi Kanapathy, ${ }^{1}$ Kok Wei Khong, ${ }^{2}$ and Rob Dekkers ${ }^{3}$ \\ ${ }^{1}$ Faculty of Business and Accountancy, University of Malaya, 50603 Kuala Lumpur, Malaysia \\ ${ }^{2}$ Taylor's Business School, Taylor's University, No. 1 Jalan Taylor's, 47500 Subang Jaya, Selangor, Malaysia \\ ${ }^{3}$ UWS Business School, University of the West of Scotland, Paisley PA1 2BE, UK \\ Correspondence should be addressed to Kanagi Kanapathy; kanagik@um.edu.my
}

Received 20 September 2013; Accepted 2 December 2013; Published 8 January 2014

Academic Editor: Nachamada Blamah

Copyright ( 2014 Kanagi Kanapathy et al. This is an open access article distributed under the Creative Commons Attribution License, which permits unrestricted use, distribution, and reproduction in any medium, provided the original work is properly cited.

\begin{abstract}
The research question is whether the positive relationship found between supplier involvement practices and new product development performances in developed economies also holds in emerging economies. The role of supplier involvement practices in new product development performance is yet to be substantially investigated in the emerging economies (other than China). This premise was examined by distributing a survey instrument (Jayaram's (2008) published survey instrument that has been utilised in developed economies) to Malaysian manufacturing companies. To gauge the relationship between the supplier involvement practices and new product development (NPD) project performance of 146 companies, structural equation modelling was adopted. Our findings prove that supplier involvement practices have a significant positive impact on NPD project performance in an emerging economy with respect to quality objectives, design objectives, cost objectives, and "time-to-market" objectives. Further analysis using the Bayesian Markov Chain Monte Carlo algorithm, yielding a more credible and feasible differentiation, confirmed these results (even in the case of an emerging economy) and indicated that these practices have a $28 \%$ impact on variance of NPD project performance. This considerable effect implies that supplier involvement is a must have, although further research is needed to identify the contingencies for its practices.
\end{abstract}

\section{Introduction}

The drive to improve product development efficiency and effectiveness, as well as to utilise suppliers' technological capabilities, is the main motive for early supplier involvement [1]. The importance of early supplier involvement, or supplier integration into new product development (NPD), has been emphasised in various research works [1-13]. Previous studies have revealed that supplier integration leads to significant improvements in NPD processes in terms of development time, cost, and quality [2, 6-8, 14-16]. For example, Cousineau et al. [17] reported that implementation of supplier integration in product development led to positive results such as enabling the supplier to meet the required timeline, providing the supplier better knowledge of the customer's needs, and enhancing customer-supplier relationships. Hence, there is little doubt that supplier involvement during NPD is beneficial for time-to-market, quality, and cost.

Although the empirical evidence found by previous studies indicates that supplier involvement leads to positive outcomes in terms of new product development performance, that finding is not necessarily valid for firms in emerging economies. It is presumed that these economies lack manufacturing and innovative capabilities [18, 19]. Looking back at the studies mentioned so far, those have often taken place in mature economies or developed nations, such as the USA $[2,3,12]$, the UK [10], Denmark [1], and Germany [20]. 
An exception would be the case of China, which has drawn attention from academics looking into innovation practices [21-25]. However, this might mean that China is a specific case from which findings might have restricted generalisation towards other emerging economies. Nevertheless, this implies that the role of supplier involvement practices in new product development is yet to be substantially investigated in the emerging economies other than China, which is the aim of our study.

The aim of the study fits with the growing trend amongst researchers to explore the relevance of existing theoretical perspectives in emerging economies [26-30]. With that same intention, we seek to explore the impact of supplier involvement practices on new product development performance in a developing economy, Malaysia. As a country that is moving "towards becoming more innovation driven" [31], its firms need to improve their new product development performance. Thus, there is a need to ascertain the level of supplier integration into new product development amongst Malaysian manufacturers and its impact on new product development performance, particularly because the manufacturing sector is still growing, while already contributing $27.5 \%$ to GDP in 2011 [32]. The objective of this research is to determine whether the positive relationship found between supplier involvement practices and new product development performance in developed economies is also valid in an emerging economy, using Malaysia as a case in point. To that purpose, this empirical study presents data and findings from a survey conducted in the manufacturing sector in Malaysia.

While studies of supplier involvement in new product development (NPD) have already taken place in generic terms related to innovation processes, fewer have taken the individual project as a starting point. Taking individual NPD projects as a starting point $[2,33,34]$ could lead to more meaningful answers on performance than can be found by discussing this in more generic terms of relationships with suppliers, as is more commonly done $[3,6,8,35,36]$; ultimately, that should lead to less bias in the responses, allowing us to draw more definite conclusions. An instrument utilised in the developed economies (developed by Jayaram) [2] was used here to ascertain the validity of the findings in an emerging economy. In addition, a more robust research method has been used to analyse the data; the Bayesian approach allowed a more credible and feasible differentiation during the analysis. Hence, this paper not only investigates the specific practices of supplier involvement in Malaysian firms but also introduces a research method for this and future research on this topic.

The paper is organised as follows. Section 2 presents a review of the literature providing current insights into supplier involvement in the form of a narrative literature review, conforming to the guidelines of Green et al. [37]. Section 3 discusses the rationale for the methodology used, including the specific data analysis techniques, structural equation modelling in combination with a Bayesian Markov Chain Monte Carlo algorithm. This is followed by a discussion of results and a conclusion in the final section.

\section{Literature Review}

The beneficiary role of suppliers and purchasing as the linchpin for new product development has been recognised, as stated above, and links to theoretical perspectives. For example, the resource-based view focuses on the strategic importance of a firm's resources and capabilities [3, 38, 39], although its propositions have been questioned [40, 41]. Referring to this theoretical perspective, Hart [42] turned to Porter's model of competitive advantage and proposed a framework that placed the purchasing function as an essential capability of an organisation. In his framework, Hart linked the activities of purchasing to the organisation's unique capabilities that are imperative in sustaining a competitive advantage. In other words, an effective purchasing function can help a firm to sustain its competitive advantage by selecting and appropriately working together with suppliers. As clearly highlighted by Ansari and Modarress [35], "an important area for purchasing and suppliers to be integrated is in the firm's product development process." Hence, the literature review focuses on the practices related to involving suppliers in new product development.

Collaboration between customer and supplier during new product development (NPD), better known as supplier integration or early supplier involvement (ESI), has been in existence for more than half a century [43]. However, it is only over the past twenty years that early supplier integration in NPD has gained much interest in academic literature [44], particularly, because supplier integration is highly influential in determining NPD performance in terms of productivity, quality, and cost [45]. As a case in point, Zirpoli and Caputo [46] studied an Italian car maker (Fiat) to explore codesign practices between Fiat and its suppliers and confirmed that supplier integration in the NPD process had benefited Fiat in achieving its NPD objectives. Furthermore, Fliess and Becker [47] studied twelve companies based in Germany and concluded that proficient coordination leads to successful supplier involvement in new product development. In addition, some other studies have confirmed the benefits of supplier involvement. Liker et al. [33] found that early supplier involvement in automobile suppliers led to cost saving and improved product quality and design. Carr and Pearson's study [3] showed that early supplier involvement had a positive influence on firms' financial performance. Handfield and Lawson [6] conducted a survey of 134 companies that revealed that supplier involvement practices improved the financial performance of the firm and product design. Therefore, the advantages of (early) supplier involvement during new product development have been broadly identified.

Recognising the need to identify the critical supplier involvement practices that lead to successful new product development (NPD), recent studies on supplier integration have focused on timing (at what stage of NPD suppliers are involved) and level of supplier integration (the depth of supplier involvement) [2]. In that regard, Mikkola and Skjoett-Larsen [1] conducted case studies in three Danish firms and pointed out that supplier integration can take place in different stages of new product development, based 
on the technical complexity of the product. Prencipe [48] also links the involvement of suppliers with the complexity of the product and the relevance of components for the total product performance. Hence, the complexity of the product, the role of supplied components in the product configuration, and stages of development have a potential impact on modes of supplier integration. In that sense, Jayaram [2] found during a survey of 338 companies in high-tech industries in the USA that communication and information sharing, design participation, and infrastructure development through supplier integration could lead to positive NPD performance in the areas of product cost, conformance quality, design quality, and time-to-market. Parker et al. [44] also found these factors to have significant impact on NPD performance. Likewise, Wasti and Liker $[43,49]$ found that there was a positive relationship between product design improvement and frequency of design-related communication with supplier. In addition, Handfield and Lawson [6] and Peterson et al. [34] found that careful selection of suppliers prior to NPD commencement and involving suppliers in setting technical goals will determine NPD performance. McGinnis and Vallopora [36] also identified similar factors for new product success. Later, van Echtelt et al. [50] conducted an in-depth four-year case study of a Dutch company and pointed out that the success of supplier integration depends on a firm's ability to manage supplier involvement effectively, to capture both short- and longterm benefits. Therefore, the complexity of the product, the role of supplied components in the product configuration, and the stages of development are ubiquitously related to the interaction with suppliers, even though they have been separately treated in academic literature so far, despite all being related to beneficial outcomes for the NPD.

Even though a wide range of studies support the notion that supplier integration brings improvements in new product development (NPD), some have raised doubts about the effectiveness of supplier involvement. For example, an early study by Ittner and Larcker [51] highlighted that supplier integration had a negative impact on NPD by increasing product development lead times. However, the researchers did acknowledge that the result could be due to insufficiencies in their measures and suggested that research on the impact of supplier on involvement practices on new product performance should be conducted in different settings, noting that this would make a substantial contribution to the study of best practices in new product development. McIvor and Humphreys' [10] study of an electronic firm and its suppliers in the UK found the presence of barriers in supplier integration in the NPD process and concluded that, for early supplier involvement to be successful, there is a need for supplier and buyer firms to increase joint problem-solving and decisionmaking, which actually points to communication and information sharing and strategic infrastructure, as proposed by Jayaram [2] and Parker et al. [44]. The word of caution is then that supplier involvement does not necessarily lead to beneficial outcomes for NPD, even though the majority of studies point in the other direction; the contingencies and conditions under which supplier integration and involvement are successful will need separate studies.
Another significant observation from the literature reviewed is that all studies on supplier involvement practices were conducted in countries from mature economies. None were conducted in countries from the emerging economies (excluding China). This validates the starting point of our study. Henceforth, there is a need for studies looking into supplier involvement in the setting of an emerging economy to ascertain whether supplier involvement practices lead to improved new product performance, just as has been proven in previous studies conducted in the mature economies.

In summary, the literature reviewed leads us to conclude that previous research focused on identifying interfirm collaborative practices (between suppliers and customers) that can positively influence NPD performance, mostly in matured economies. Few studies identified barriers and problems in supplier integration in NPD [10,51], but these studies stressed the need to improve joint problem-solving and decision-making and suggested more studies in different settings to ascertain best practices in NPD. Amongst the supplier involvement practices identified as influencing NPD performance, the main emphasis has been on two interfirm collaborative practices, that is, communication and information sharing and strategic infrastructure $[2,16,44]$. Hence, to address this gap in the literature, this research attempts to determine whether these supplier involvement practices (communication and information sharing and strategic infrastructure) affect new product development project performance in terms of conformance with performance objectives in the setting of a developing economy. The following depicts the proposed conceptual framework of this study. The parameters derived in the framework are discussed in the following section.

\section{Research Method}

This is a confirmatory study regarding beneficial supplier involvement practices during new product development conducted in an emerging economy, specifically in the Malaysian manufacturing sector. The Malaysian manufacturing sector contributed $27.5 \%$ to GDP in 2011 [32]. Small, emerging economies such as Malaysia need to increase their competitive advantage through advances in innovation, technology, and value addition. This can transform a "low value assembly line to one that is driven by innovation" [52]. Innovation relates to new product development performance. As previous studies in developed countries have shown that supplier involvement leads to positive outcomes in terms of new product development performance, this study intends to ascertain the impact of supplier involvement practices on new product development performance in a developing economy: Malaysia.

Jayaram [2] provides a survey instrument for this objective. The constructs used in our study were taken from his study to measure supplier involvement practices: communication and information sharing and strategic infrastructure (Table 1). In addition, the constructs used to measure individual NPD project performances (Table 2) are quality, design, cost, and time-to-market objectives; these are commensurate 
TABLE 1: The variables manifesting supplier involvement practices.

\begin{tabular}{ll}
\hline Variable label & Variable description \\
\hline C1 & Participation of key suppliers in NPD team \\
C2 & Direct communication with key suppliers \\
C3 & Shared design knowledge with key suppliers \\
C4 & Common linked information systems (EDI, \\
& CAD/CAM) \\
C5 & Shared education and training programs with key \\
C6 & Suppliers \\
\hline
\end{tabular}

TABLE 2: The variables manifesting project performance.

\begin{tabular}{ll}
\hline Variable label & Variable description \\
\hline E1 & Conformance to quality objectives set \\
E3 & Conformance to design objectives set \\
E4 & Conformance to cost objectives set \\
\hline
\end{tabular}

with other studies like those of Ragatz et al. [53] and Johnsen [54]. These constructs in the survey instrument replicate the ones used by Jayaram [2] in his study of 338 companies in high-tech industries in the USA; this will allow a direct comparison of findings.

3.1. Survey Instrument. Relevant sections of Jayaram's published survey form [2] were slightly modified for use in this survey. A pilot study was conducted to fine-tune the survey form before distributing it to manufacturing firms throughout Malaysia. In the first section of the survey, the respondents were asked to denote the extent of supplier involvement practices used in new product development (where 0 means not used and 10 means used to a great extent). The supplier involvement practices are listed in Table 1. The first three items represented communication and information sharing while the next three items represented strategic infrastructure. In the second section of the survey, the respondents were requested to rate the level of NPD project performance in four different aspects (where 0 means significantly worse than expectations and 10 means significantly better than expectations). These measures of NPD project performance are listed in Table 2.

Since the unit of analysis was a new product development project, the questionnaire specified the desired respondent as a person (at executive level and above) from design/ engineering/quality/production/purchasing, who had been engaged in all stages of the project. The respondents were requested to answer the survey based on a new product development project concluded in the past three years for which they were either project leaders or project members.

3.2. Data Collection. The survey instrument was distributed using two channels. Questionnaires were distributed to managers from the manufacturing sector who attended training sessions at the Federation of Malaysian Manufacturers (FMM) Institute. This was augmented by questionnaires that were distributed to the researchers' contacts in the manufacturing sector. The administering of questionnaires was carefully done in order to ensure that only relevant respondents filled in the survey forms. After 12 weeks, the researchers had obtained a total of 168 responses. Of these 168,22 were discarded due to noncompletion or $50 \%$ or above missing values. As a result, 146 responses were available for further analysis. Based on the sample size of 146, further analysis is viable.

3.3. Data Analysis. Because this is a confirmatory study conducted in an emerging economy, there is a need to apply a strong, robust methodology. The path diagram in Figure 1 depicts the conceptual framework developed to address the research objective of this paper. The path diagram indicates a causal relationship between supplier involvement practices and NPD project performance. To empirically gauge the extent of the relationship between supplier involvement practices and project performance, a series of techniques was introduced. These techniques are the reliability test, exploratory factor analysis (EFA), confirmatory factor analysis (CFA) and structural equation modelling (SEM). The reliability test is a measure of internal consistency of a summated scale of the variables manifesting the hypothetical concepts, the supplier involvement practices, and the NPD project performance (see Tables 1 and 2). These techniques have been supplemented by a Bayesian Markov Chain Monte Carlo algorithm to ensure that a robust method is utilised in the statistical analysis. It is noteworthy that, for reasons of robustness with respect to analysis, this approach has gained popularity in evolutionary biology [55-57] and to a lesser extent in econometrics $[58,59]$ and engineering [60]. Commensurate with the research objectives, the solid approach of combining a Bayesian method with more traditional SEM will allow us to draw more definite conclusions about the relationship between supplier involvement practices and new product development project performance.

This deviates from the research designs used for investigating supplier involvement practices so far, which include qualitative analysis $[35,46,47]$, variance and means analysis $[8,36,61]$, regression analysis $[2,6,14,33,34]$, and sole SEM $[3,12,44]$. Hence, this confirms the unique and robust approach taken in our study as new to the domain.

\section{Analysis of Results}

The first step in the analysis is determining the reliability and consistency of the collected data. For that purpose, a recommended threshold of 0.7 for the reliability test depicts a meaningful manifestation of variables on their respective concepts $[62,63]$. The reliability test was carried out using SPSS, a statistical software package by IBM. Results show, in Table 3, that "supplier involvement practices" have a Cronbach's alpha of 0.882 while "NPD project performance" has 0.928 . Both concepts are well above the 0.7 threshold and therefore have internal consistency amongst the variables in a summated scale. In short, it can be seen that the questionnaire 


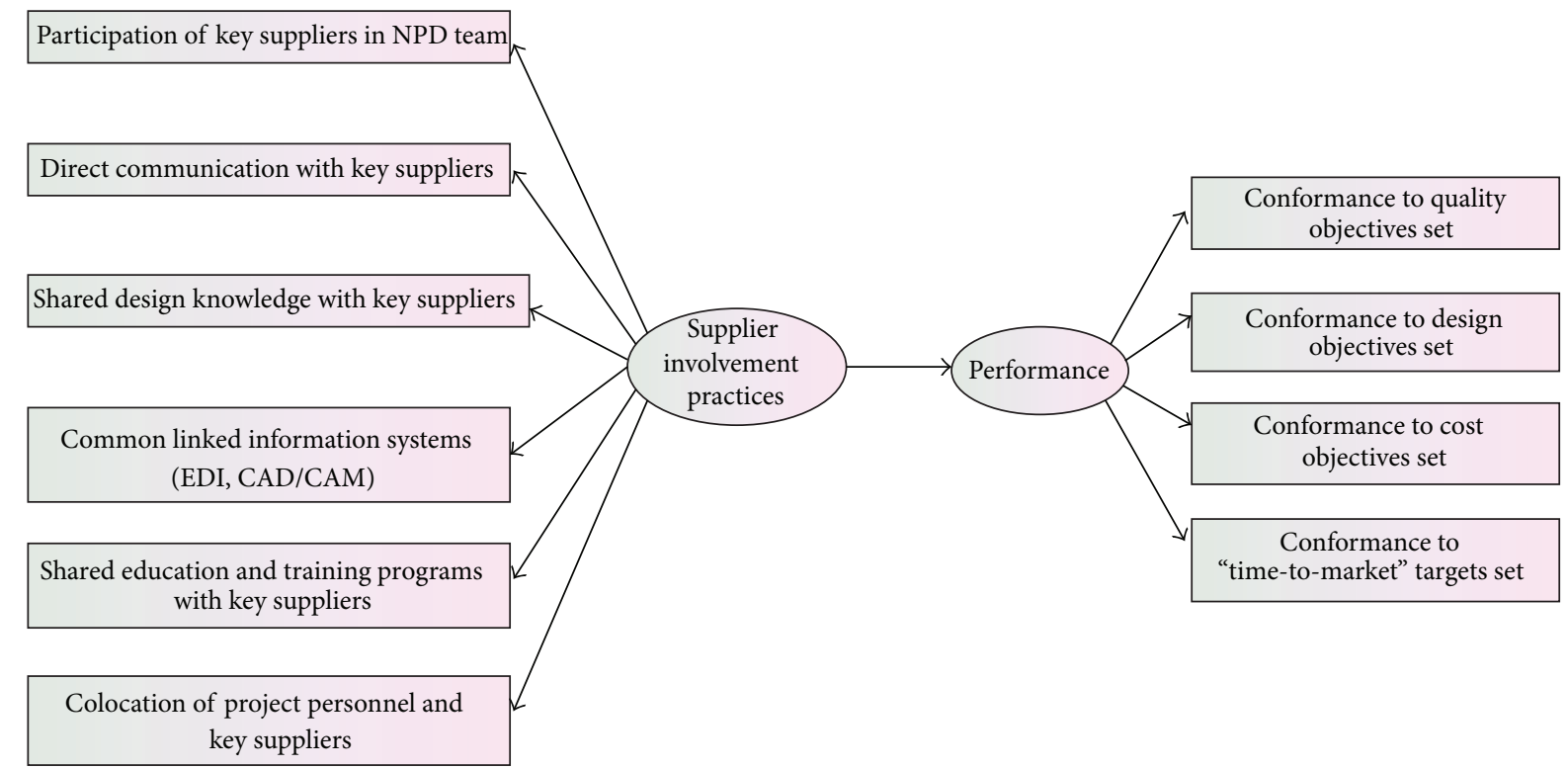

FIGURE 1: Shows the conceptual framework of supplier involvement practices.

is measuring the antecedents of the concept in a consistent and reliable way.

A next step in the analysis is the extraction of relevant factors. In that respect, exploratory factor analysis (EFA) is conducted to examine "possible relationships in only the most general form and then allows the multivariate technique to estimate relationships" [66, page 580]. Ultimately, the objective of EFA is to reduce the number of variables manifesting the hypothetical concepts into a manageable set of factors (see Table 4). It is recommended that factors are extracted using the principal component matrix (PCM) and rotated via Varimax. Two factors were extracted as they were clear factor structures, in the form of factor 1 (manifested by variables E1,E2,E3, and E4) and factor 2 (manifested by variables $C 1, C 2, \ldots$, C6). Results from the Kaiser-MeyerOlkin measure $(0.842)$ and Bartlett's Test $(P$ value $<0.01)$ show that the factors extracted have high correlation amongst manifesting variables. These highly correlated manifesting variables will enable clear factor structure detection.

4.1. Factor Analysis. This brings the analysis to the step of excavation of constructs. When conducting confirmatory factor analysis (CFA), also known as the measurement model, variables are assigned to manifest a specific factor, now called a construct. Variables with high factor loadings are chosen to manifest the construct. Factor loadings above 0.6 within the complex factor structures are the recommended threshold [64]. Based on Table 4, the confirmed variables manifesting the respective constructs are as follows: participation of key suppliers $(C 1)$, direct communication with key suppliers $(C 2)$, shared design knowledge with key suppliers (C3), common linked information systems $(C 4)$, shared education and training programmes with key suppliers (C5) and co-location of project personnel and key suppliers (C6) manifest supplier involvement practices, while conforming to quality objectives
(E1), design objectives (E2), cost objectives (E3), and "timeto-market" targets (E4) manifest project performance.

From the results of CFA, a series of equations can be notated on the two constructs. In order to do so, let the measurement models of supplier involvement practices and project performance be defined by the vectors of observed variables, where $C=\left(x_{1}, x_{2}, \ldots, x_{6}\right)$ and $E=\left(y_{1}, y_{2}, y_{3}, y_{4}\right)$. Then let the general equation of the measurement models be given as

$$
\begin{aligned}
& C=\Lambda_{x} \xi+\delta, \\
& E=\Lambda_{y} \eta+\varepsilon,
\end{aligned}
$$

where $X$ and $Y$ are the vectors of observed variables of the constructs $C$ and $E$, respectively. $\xi$ is the exogenous construct and $\delta$ is the measurement error for the constructs (note $E(\delta)=0$ ) [65]. $\Lambda$ represents the regression weights between the observed variables and constructs. Equations (1) and (2) are general equations of the measurement model in SEM $[66,67]$. Further corresponding equations for (1) could be written as follows:

Exogenous constructs

$$
\left(\begin{array}{l}
x_{1} \\
x_{2} \\
x_{3} \\
x_{4} \\
x_{5} \\
x_{6}
\end{array}\right)=\left(\begin{array}{l}
\lambda_{1}^{x} \\
\lambda_{2}^{x} \\
\lambda_{3}^{x} \\
\lambda_{4}^{x} \\
\lambda_{5}^{x} \\
\lambda_{6}^{x}
\end{array}\right) \xi+\left(\begin{array}{l}
\delta_{1} \\
\delta_{2} \\
\delta_{3} \\
\delta_{4} \\
\delta_{5} \\
\delta_{6}
\end{array}\right)
$$


TABLE 3: The reliability of supplier involvement practices and NPD project performance.

\begin{tabular}{|c|c|c|c|c|}
\hline Concepts & & Variables & $\begin{array}{l}\text { Corrected item-total } \\
\text { correlation }\end{array}$ & $\begin{array}{l}\text { Cronbach's } \\
\text { alpha }\end{array}$ \\
\hline \multirow{6}{*}{$\begin{array}{l}\text { Supplier involvement } \\
\text { practices }\end{array}$} & $C 1$ & Participation of key suppliers & 0.638 & \multirow{6}{*}{0.882} \\
\hline & $C 2$ & Direct communication with key suppliers & 0.769 & \\
\hline & C3 & Shared design knowledge with key suppliers & 0.826 & \\
\hline & C4 & $\begin{array}{l}\text { Common linked information systems (EDI, } \\
\text { CAD/CAM) }\end{array}$ & 0.585 & \\
\hline & C5 & $\begin{array}{l}\text { Shared education and training programs with key } \\
\text { suppliers }\end{array}$ & 0.679 & \\
\hline & C6 & Co-location of project personnel and key suppliers & 0.666 & \\
\hline \multirow{4}{*}{$\begin{array}{l}\text { NPD project } \\
\text { performance }\end{array}$} & E1 & Conformance to quality objectives set & 0.874 & \multirow{4}{*}{0.928} \\
\hline & $E 2$ & Conformance to design objectives set & 0.849 & \\
\hline & E3 & Conformance to cost objectives set & 0.807 & \\
\hline & E4 & Conformance to "time-to-market" targets set & 0.807 & \\
\hline
\end{tabular}

TABLE 4: The factors extracted via principal component analysis and rotated via Varimax.

\begin{tabular}{lcc}
\hline & \multicolumn{2}{c}{ Component } \\
& 1 & 2 \\
\hline$C 1$ & & 0.642 \\
$C 2$ & & 0.745 \\
$C 3$ & & 0.851 \\
$C 4$ & & 0.766 \\
$C 5$ & & 0.714 \\
$C 6$ & & 0.831 \\
$E 1$ & 0.918 & \\
$E 2$ & 0.877 & \\
$E 3$ & 0.856 & \\
$E 4$ & 0.868 & \\
\hline
\end{tabular}

Endogenous construct

$$
\left(\begin{array}{l}
y_{1} \\
y_{2} \\
y_{3} \\
y_{4}
\end{array}\right)=\left(\begin{array}{l}
\lambda_{1}^{y} \\
\lambda_{2}^{y} \\
\lambda_{3}^{y} \\
\lambda_{4}^{y}
\end{array}\right) \eta+\left(\begin{array}{l}
\varepsilon_{1} \\
\varepsilon_{2} \\
\varepsilon_{3} \\
\varepsilon_{4}
\end{array}\right)
$$

Structural equation modelling (SEM) is a technique encompassing structure analysis, latent variable analysis, confirmatory factor analysis, path analysis, and linear structural relation analysis [66, page 584]. SEM consists of the structural model and measurement model (CFA). The former is made up of a "set of one or more dependence relationships linking the hypothesized model's constructs" [66, page 583]. Subsequent to CFA, SEM is conducted to analyse a series of interdependent regression equations simultaneously. Its ability in simultaneous estimation of regression equations makes it the most suitable analysis for this research. In order to mathematically correspond to the structural model, let the general equation of the structural model be given as

$$
\eta=\gamma \xi+\zeta
$$

where $\gamma$ is the associations between the exogenous constructs $(\xi)$ and endogenous construct $(\eta) . \zeta$ is the measurement error for the concept $(\eta)$ as shown in Figure 2 (note $E(\zeta)=0, \beta \eta=$ 0 ) [65]. The figure shows the causal relationships between the structural and measurement models given in (1) and (5). Based on the equations, the structural model is therefore notated as

$$
\eta=\lambda_{1,1} \xi+\zeta
$$

Based on the results in Figure 2, (6) can be simplified to:

$$
\eta=0.53 \xi \text {. }
$$

Referring to Figure 2, the results show that the model is estimated with a chi-square of 38.024 and degrees of freedom of 34 . These results represent an overidentified model. The chisquare $P$-value of the model is reported at 0.291 , indicating that the model has a good fit. The absolute fit measure is good, as RMSEA is 0.067 (below the 0.08 threshold). The results imply that the model fits the variance-covariance matrix. Incremental fit measures are also good, with both Incremental Fit Index (IFI) and Tucker-Lewis Index (TLI) reported at 0.977 and 0.968 (above the 0.90 threshold). These results indicate that the model is robust and met the requirements of a good model. There is good model parsimony, since the chi-square/degrees of freedom $\left(\chi^{2} / d f=\right.$ $1.118)$ is between 1 and 2 . This result suggests that the model is estimated without overfitting it with too many parameters. The model also depicts that supplier involvement practices explain $28 \%$ of total variance of NPD project performance; this constitutes a major finding of the analysis.

4.2. Bayesian Estimation. While in general the model has achieved overall goodness of fit measures, to further substantiate the results of fit indices a Bayesian estimation is 

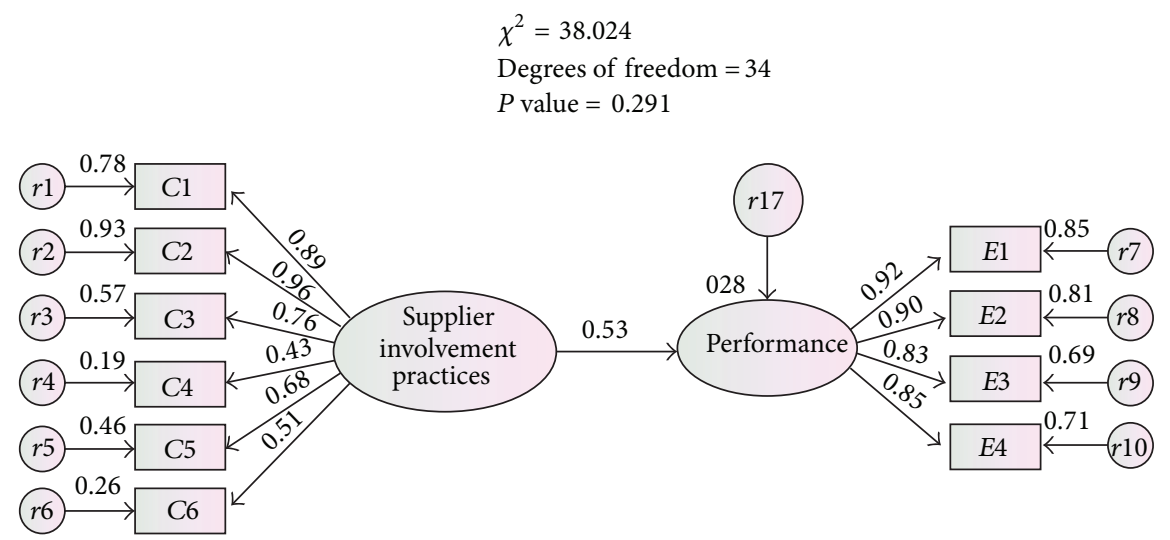

FIGURE 2: Shows the results of SEM. Note: results are depicted in standardized estimates.

conducted to investigate the robustness of the findings (both the association and the $28 \%$ of total variance of NPD project performance). The Bayesian estimation approach is useful when applied to models estimated using maximum likelihood estimation (MLE) in SEM, where the measurement models in the structural model are latent in nature. Furthermore, this approach is very useful when the sample size is small, which is the case for the 146 responses to the survey. In this paper the Bayesian estimation approach is used to substantiate the SEM model validation of substantive theory (via hypotheses shown earlier) that uses stringent MLE and $\chi^{2}$ estimation procedures [68]. The Bayesian approach, unlike MLE, looks at the parameter estimates as variables that then diffuse the posterior distribution from mean, median, and mode. For that purpose, the Bayesian approach on the SEM model is computed via the Markov Chain Monte Carlo (MCMC) algorithm. It is hoped that the Bayesian SEM (BSEM) can estimate results that are more reflective of the substantive theories.

The computational efforts in this paper are done using SPSS AMOS, a statistical software package from IBM. The BSEM MCMC algorithm computed by AMOS diffuses the posterior distribution through the drawing of random values of parameters that are viewed as variables [59]. The posterior mean values are estimated based on the averages of drawn analysis samples generated by MCMC. Based on the SEM model, AMOS drew 74,500 analysis samples from the dataset and discarded 500 burn-in samples from the 74,500 analysis samples to allow a clearer estimation of the posterior distribution of the supplier involvement practices $\rightarrow$ NPD project performance. The MCMC BSEM estimation via AMOS uses a random number seed where the model is simulated on a range of random numbers invoked by the respective seed.

From the analysis samples drawn, the posterior distribution is present in Figure 3; this figure depicts the similarity between the first and last thirds of the analysis samples in the posterior distribution. This invariably suggests that the features of the posterior distribution of supplier involvement practices $\rightarrow$ NPD project performance are clearly identified. The posterior mean of supplier involvement practices $\rightarrow$ NPD project performance appears to be approximately 0.38 , which is rather similar to the nonstandardised regression weights (0.37) of the path diagram. In short, the generated posterior mean could be generated into (5), where we contrast both models as follows:

$$
\begin{aligned}
& \eta=0.37 \xi+\zeta, \\
& \eta=0.38 \xi+\zeta,
\end{aligned}
$$

where (8) is the structural model based on unstandardised $\gamma$ while (9) is the BSEM MCMC model based on posterior mean.

The min-max threshold of the posterior distribution is between 0.150 and 0.689 . This suggests that the supplier involvement practices $\rightarrow$ NPD project performance association is always positive, also implying evidential support that the true value of the parameter is larger than zero and hence supporting the literature; this is also consistent with the SEM results.

The trace plot shown in Figure 4 suggests that the resonating patterns of supplier involvement practices $\rightarrow$ NPD project performance converged between the threshold of 0.150 and 0.689 . The plot also depicts the consistency of the resonating pattern. There are some spikes, approximately at iterations 15,000 and 57,000. However these spikes were not regular and did not affect the convergence of the distribution.

The autocorrelation plot in Figure 5 depicts the convergence that took place when the MCMC method was deployed. The correlation between the drawn samples started to decay to 0.50 at around lag-17 and the autocorrelation coefficient is close to 0 in lag- 90 henceforth. At this point, convergence to the posterior distribution is achieved, indicating that the 500-burn-in drawn samples previously mentioned were more than adequate [59]. More specifically, the convergence of posterior distribution for the BSEM is 1.005 and the posterior predictive $P$-value is 0.001 . In short, when convergence happened at lag-90, the posterior summaries of the distribution stabilised, implying that the initial samples drawn no longer correlate with the samples drawn last. Based on these results the posterior mean converged, which is approximately similar to the nonstandardised regression weights, portraying an excellent predictive value to the association between supplier involvement practices and NPD project performance. 


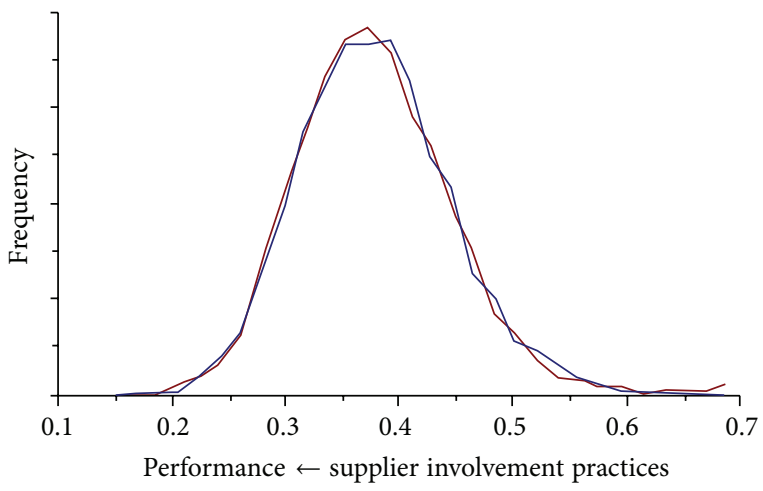

FIGURE 3: The posterior distribution of the first and last thirds of the drawn analysis samples of supplier involvement practices $\rightarrow$ NPD project performance. Note: Blue depicts post-convergence posterior distribution and red pre-convergence posterior distribution.

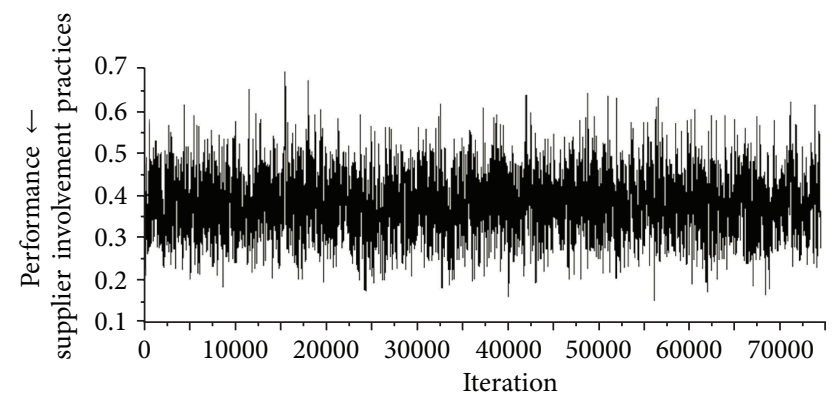

FIGURE 4: Shows the trace plot of supplier involvement practices $\rightarrow$ NPD project performance.

We define the total variance $\left(R^{2}\right)$ of NPD project performance as the square of the association between supplier involvement practices and NPD project performance $(\lambda)$. Since the nonstandardised $\lambda$ of the SEM model is similar to the posterior mean of supplier involvement practices $\rightarrow$ NPD project performance, we can deduce that the BSEM results confirm the extent of the impact of supplier involvement practices on NPD project performance. Furthermore, the BSEM simulation results also showed that there were no multicollinearity problems as the correlation between the two constructs was between 0.4 and 0.5 [69]. This finding was substantiated by the discriminant validity proposed by Fornell and Larcker [70], where both constructs were distinct. Based on this measure, the average variance extracted (AVE) of supplier involvement practices (0.5328) and NPD project performance (0.7674) were greater than the square of correlation between the two constructs (0.2767). Additionally, the AVE of these constructs showed convergent validity as they met the threshold of 0.5 and above [71].

\section{Discussion of Findings}

This study investigated the association between supplier integration practices and new NPD project performance within a sample of 146 companies in an emerging economy, Malaysia. We examined the association between key factors

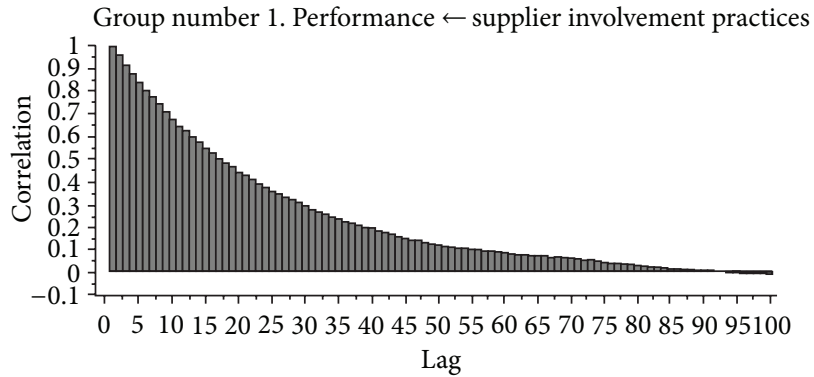

FIGURE 5: Shows the autocorrelation plot of supplier involvement practices $\rightarrow$ NPD project performance.

of supplier involvement practices (communication and information sharing, and development of strategic infrastructure) and NPD project performance. The project performance measures include conformance to quality objectives, design objectives, cost objectives, and "time-to-market" objectives set. We proposed that there is a positive association between supplier involvement practices and NPD project performance. Our results using SEM show that there is a positive association between supplier involvement practices and NPD project performance. Further analysis using a Bayesian MCMC algorithm confirmed that the supplier involvement practices $\rightarrow$ NPD project performance association is always positive, also implying evidential support that the true value of the parameter is larger than zero and hence supporting the literature.

The findings of this study are comparable with the study conducted by Jayaram [2] in the USA, a mature, developed economy. Jayaram's large-scale study focused on 338 firms manufacturing high-tech products and was the first study to use NPD project performance measures, instead of firm performance or manufacturing performance measures, to assess the impact of supplier involvement practices. Jayaram found that communication and information sharing and developing strategic infrastructure were the two main supplier integration factors that positively influenced NPD project performance, measured in terms of product cost, conformance quality, design quality, and "time-to-market." Our study confirmed the importance of communication and information sharing and developing strategic infrastructure in NPD project performance. In addition, our study did not specifically focus on firms producing high-tech products, as Jayaram's study did, but considered all subsectors of the Malaysian manufacturing sector. Thus, the findings of this study can be generalised to the entire manufacturing sector in Malaysia and potentially to all emerging economies.

Despite our strong findings, research on supplier involvement is marred by contradictions. This study provides support for initial findings by Swink et al. [13] that supplier involvement reduced development time (in our study, this is part of time-to-market) in new product development projects. However, this contradicts findings by Trygg [72] and Ittner and Larcker [51] that showed that supplier involvement in NPD did not have substantial positive impact on development time. In our study, supplier involvement practices 
had the least impact on time-to-market (E4) but still had a significant positive impact.

More interestingly, our study has provided a figure for the impact of supplier involvement practices on the performance of new product development projects. Because of the reliability of the structural equation modelling (SEM) outcomes, the analysis shows that $28 \%$ of total variance of NPD project performance can be related to supplier involvement practices. The use of the Bayesian MCMC algorithm confirmed that the relationship between the two constructs is constantly positive. This indicates a relatively high impact of supplier involvement practices despite its controversies.

\section{Concluding Remarks}

Our findings proved that supplier involvement practices have a significant positive impact on NPD project performance in an emerging economy in the areas of quality objectives, design objectives, cost objectives, and "time-to-market" objectives; consistency with Jayaram's study [2] confirms that supplier involvement practices have a positive impact on NPD performance in an emerging economy just as they do in mature, developed economies. Our research findings are also comparable and consistent with the findings of Clark [14], Gadde and Snehota [73], and Rubenstein and Ettlie [74].

6.1. Practical Implications. Stiff competition throughout the world has pushed firms to strive harder to produce highquality, innovative products. This has been quite a challenge for firms in developing economies. Competition is no longer between firms-it is often suggested that competition is now between supply chains [75]. This study provides strong encouragement for firms in emerging economies to start early collaboration with suppliers in terms of communication and information sharing and strategic infrastructure development, to realise worthy improvements in terms of new product quality, design, cost, and "time-to-market."

Indirectly, this research has also highlighted the potential role of the purchasing function in firms' competitive position. During the analysis using structural equation modelling it emerged that supplier involvement practices account for $28 \%$ of total variance of NPD project performance; this is a significant number, even though it might depend on the complexity of products, the role of supplied components in the product configuration, and the stages of NPD. It is the purchasing function-not to be confused with a department per se-that needs to facilitate communication, information sharing, and development of a strategic infrastructure. Conversely, in reality, the indirect contributions of purchasing, in terms of product quality, innovation, and lead time, can be significant compared to direct contributions in terms of cost savings [45]. In that sense, the purchasing function has a noteworthy influence on manufacturing quality and new product development in addition to delivery and cost [76]. Our study confirms that the purchasing function has evolved to be a major contributor to organisational competitiveness, as Cavinato [77] notes.
6.2. Further Research. The model also indicates that supplier involvement practices explain $28 \%$ of total variance of NPD project performance. It was possible to extract this figure using the performance of individual projects as a differentiator for determining the impact of individual supplier involvement practices. Not only does this mean that manufacturing might benefit from this insight, but we also suggest that this research should be extended to the services sector, to investigate the impact of early supplier involvement on new service development. However, it also means that further research is needed to confirm this figure for both developed and emerging economies and for the services sector.

Furthermore, the literature review identified that separate studies are required to look into the contingencies and conditions under which supplier integration and involvement are successful. This should be positioned within Tidd's [78] call for more integrated approaches to innovation management and Damanpour's [79] plea for considering contingencies. Specifically, in the literature review, we have identified the complexity of the product, the role of supplied components in the product configuration, and stages of development as contingencies. Exploration of the factors influencing supplier integration into NPD will provide useful insights for practitioners in order to focus on the factors that have positive influence on supplier involvement practices. Hence, this study needs augmentation by research that explores the specific contingencies for supplier involvement practices to be most effective.

In any case, the survey instrument used in this research has proven to be a reliable tool for gauging the impact of supplier involvement practices on NPD project performance. The SEM algorithm proposed is also a feasible and practical approach to empirical measurement of the association of both constructs mentioned above. We believe that SEM MCMC provides a credible approach with which to substantiate associations in the structural model of SEM, especially as SEM incorporates stringent model testing and is very sensitive to large sample sizes. This study could be further improved should the sample size increase, as possible multigroup SEM analyses could then be conducted.

The limitation of this research is that the data relied on a single NPD's project performance per firm. The respondents' selection of NPD projects could have caused bias in the results, especially in terms of NPD project performance. Assessing NPD performance in general terms, as is commonly done $[3,6,36,61]$, leads to less specific outcomes. A possible extension of the research approach to cover more NPD projects per firm could overcome this but might be more challenging; again, multigroup SEM analyses might be useful in this matter.

6.3. Conclusion. Despite the need to search for contingencies and the limitations noted above, our study leaves little doubt regarding the positive impact of supplier involvement practices on NPD project performance. The role of facilitating communication, information sharing, and development of a strategic infrastructure as constituent components of supplier 
involvement practices has also been confirmed. Hence, both researchers and practitioners could take this as a starting point for successful new product development projects.

\section{Conflict of Interests}

The authors declare that there is no conflict of interests regarding the publication of the article.

\section{Acknowledgments}

The authors acknowledge the financial support provided by the University of Malaya, Research Grant no. RG068-10SBS. The authors also thank Abdul Razak Ibrahim, Chua Hock Joo, and the Federation of Malaysian Manufacturers Institute for their assistance in data collection.

\section{References}

[1] J. H. Mikkola and T. Skjoett-Larsen, "Early supplier involvement: implications for new product development outsourcing and supplier-buyer interdependence," Global Journal of Flexible Systems Management, vol. 4, pp. 31-41, 2003.

[2] J. Jayaram, "Supplier involvement in new product development projects: dimensionality and contingency effects," International Journal of Production Research, vol. 46, no. 13, pp. 3717-3735, 2008.

[3] A. S. Carr and J. N. Pearson, "The impact of purchasing and supplier involvement on strategic purchasing and its impact on firm's performance," International Journal of Operations and Production Management, vol. 22, no. 9-10, pp. 1032-1053, 2002.

[4] J. Dyer and W. Ouchi, "Japanese-style partnerships: giving companies a competitive edge," Sloan Management Review, vol. 35, pp. 51-63, 1993.

[5] A. K. Gupta and W. E. Souder, "Key drivers of reduced cycle time," Research Technology Management, vol. 41, no. 4, pp. 3843, 1998.

[6] R. B. Handfield and B. Lawson, "Integrating suppliers into new product development," Research Technology Management, vol. 50, no. 5, pp. 44-51, 2007.

[7] R. B. Handfield and C. Bechtel, "The role of trust and relationship structure in improving supply chain responsiveness," Industrial Marketing Management, vol. 31, no. 4, pp. 367-382, 2002.

[8] R. B. Handfield, G. L. Ragatz, K. J. Petersen, and R. M. Monczka, "Involving suppliers in new product development?" California Management Review, vol. 42, no. 1, pp. 59-82, 1999.

[9] C. Luo, D. N. Mallick, and R. G. Schroeder, "Collaborative product development: exploring the role of internal coordination capability in supplier involvement," European Journal of Innovation Management, vol. 13, no. 2, pp. 244-266, 2010.

[10] R. McIvor and P. Humphreys, "Early supplier involvement in the design process: lessons from the electronics industry," Omega, vol. 32, no. 3, pp. 179-199, 2004.

[11] M. A. M. Primo and S. D. Amundson, "An exploratory study of the effects of supplier relationships on new product development outcomes," Journal of Operations Management, vol. 20, no. 1, pp. 33-52, 2002.

[12] G. L. Ragatz, R. B. Handfield, and K. J. Petersen, "Benefits associated with supplier integration into new product development under conditions of technology uncertainty," Journal of Business Research, vol. 55, no. 5, pp. 389-400, 2002.

[13] M. L. Swink, J. C. Sandvig, and V. A. Mabert, "Customizing concurrent engineering processes: five case studies," Journal of Product Innovation Management, vol. 13, no. 3, pp. 229-244, 1996.

[14] K. B. Clark, "Project scope and project performance: the effect of parts strategy and supplier involvement on product development," Management Science, vol. 35, pp. 1247-1263, 1989.

[15] K. Imai, I. Nonaka, and H. Takeuchi, "Managing the new product development process: how Japanese companies learn and unlearn," in The Uneasy Alliance: Managing the ProductivityTechnology Dilemma, R. H. Hayes, K. Clark, and Lorenz, Eds., pp. 337-375, 1985.

[16] X. A. Koufteros, T. C. Edwin Cheng, and K.-H. Lai, “"Black-box” and "gray-box" supplier integration in product development: antecedents, consequences and the moderating role of firm size," Journal of Operations Management, vol. 25, no. 4, pp. 847870, 2007.

[17] M. Cousineau, T. W. Lauer, and E. Peacock, "Supplier source integration in a large manufacturing company," Supply Chain Management, vol. 9, no. 1, pp. 110-117, 2004.

[18] G. D. Bruton and Y. Rubanik, "Resources of the firm, Russian high-technology startups, and firm growth," Journal of Business Venturing, vol. 17, no. 6, pp. 553-576, 2002.

[19] J. Li, D. Chen, and D. M. Shapiro, "Product innovations in emerging economies: the role of foreign knowledge access channels and internal efforts in Chinese firms," Management and Organization Review, vol. 6, no. 2, pp. 243-266, 2010.

[20] K. E. Gruner and C. Homburg, "Does customer interaction enhance new product success?" Journal of Business Research, vol. 49, no. 1, pp. 1-14, 2000.

[21] T. Feng, L. Sun, and Y. Zhang, "The effects of customer and supplier involvement on competitive advantage: an empirical study in China," Industrial Marketing Management, vol. 39, no. 8, pp. 1384-1394, 2010.

[22] G. Q. Huang, J. Huang, and K. L. Mak, "Early supplier involvement in new product development on the internet: implementation perspectives," Concurrent Engineering Research and Applications, vol. 8, no. 1, pp. 40-49, 2000.

[23] Y.-Y. Jiao, J. Du, R. J. Jiao, and D. L. Butler, “Operational implications of early supplier involvement in semiconductor manufacturing firms: a case study," Journal of Manufacturing Technology Management, vol. 19, no. 8, pp. 913-932, 2008.

[24] A. K. W. Lau, "Supplier and customer involvement on new product performance: contextual factors and an empirical test from manufacturer perspective," Industrial Management and Data Systems, vol. 111, no. 6, pp. 910-942, 2011.

[25] M. Lockstrom, J. Schadel, R. Moser, and N. Harrison, "Domestic supplier integration in the chinese automotive industry: the buyer's perspective," Journal of Supply Chain Management, vol. 47, no. 4, pp. 44-63, 2011.

[26] G. D. Bruton, G. G. Dess, and J. J. Janney, "Knowledge management in technology-focused firms in emerging economies: caveats on capabilities, networks, and real options," Asia Pacific Journal of Management, vol. 24, no. 2, pp. 115-130, 2007.

[27] X. Fu, C. Pietrobelli, and L. Soete, "The role of foreign technology and indigenous innovation in the emerging economies: technological change and catching-up," World Development, vol. 39, no. 7, pp. 1204-1212, 2011. 
[28] R. E. Hoskisson, R. A. Johnson, L. Tihanyi, and R. E. White, "Diversified business groups and corporate refocusing in emerging economies," Journal of Management, vol. 31, no. 6, pp. 941-965, 2005.

[29] K. E. Meyer, "Asian contexts and the search for general theory in management research: a rejoinder," Asia Pacific Journal of Management, vol. 24, no. 4, pp. 527-534, 2007.

[30] A. S. Tsui, "Contextualization in Chinese management research," Management and Organization Review, vol. 2, pp. 1-13, 2006.

[31] X. Sala-i-Martin, "Global competitiveness report 2011-2012, 2011, Geneva," World Economic Forum, p. 29, 2011.

[32] B. N. Malaysia, Quarterly bulletin, Bank Negara Malaysia, 2012.

[33] J. K. Liker, R. R. Kamath, and S. N. Wasti, "Supplier involvement in design: a comparative survey of automotive suppliers in the USA, UK and Japan," International Journal of Quality Science, vol. 3, pp. 214-238, 1998.

[34] K. J. Petersen, R. B. Handfield, and G. L. Ragatz, "Supplier integration into new product development: coordinating product, process and supply chain design," Journal of Operations Management, vol. 23, no. 3-4, pp. 371-388, 2005.

[35] A. Ansari and B. Modarress, "Quality function deployment: the role of suppliers," Journal of Supply Chain Management, vol. 30, pp. 27-35, 1994.

[36] M. A. McGinnis and R. M. Vallopra, "Purchasing and supplier involvement: issues and insights regarding new product success," Journal of Supply Chain Management, vol. 35, pp. 4-15, 1999.

[37] B. N. Green, C. D. Johnson, and A. Adams, "Writing narrative literature reviews for peer-reviewed journals: secrets of the trade," Journal of Chiropractic Medicine, vol. 5, no. 3, pp. 101-117, 2006.

[38] J. Barney, "Firm resources and sustained competitive advantage," Journal of Management, vol. 17, pp. 99-120, 1991.

[39] B. Wernerfelt, "A resource-based view of the firm," Strategic Management Journal, vol. 5, pp. 171-180, 1984.

[40] V. Mahnke, "The process of vertical dis-integration: an evolutionary perspective on outsourcing," Journal of Management and Governance, vol. 5, no. 3-4, pp. 353-379, 2001.

[41] R. L. Priem and J. E. Butler, "Is the resource-based "view" a useful perspective for strategic management research?" Academy of Management Review, vol. 26, no. 1, pp. 22-40, 2001.

[42] S. L. Hart, "A natural-resource-based view of the firm," Academy of Management Review, pp. 986-1014, 1995.

[43] S. N. Wasti and J. K. Liker, "Risky business or competitive power? supplier involvement in Japanese product design," Journal of Product Innovation Management, vol. 14, no. 5, pp. 337-355, 1997.

[44] D. B. Parker, G. A. Zsidisin, and G. L. Ragatz, "Timing and extent of supplier integration in new product development: a contingency approach," Journal of Supply Chain Management, vol. 44, no. 1, pp. 71-83, 2008.

[45] A. J. van Weele, "Purchasing and supply chain management: analysis," in Planning and Practice, Thomson Learning, London, UK, 3rd edition, 2002.

[46] F. Zirpoli and M. Caputo, "The nature of buyer-supplier relationships in co-design activities: the Italian auto industry case," International Journal of Operations and Production Management, vol. 22, no. 12, pp. 1389-1410, 2002.

[47] S. Fliess and U. Becker, "Supplier integration-controlling of codevelopment processes," Industrial Marketing Management, vol. 35, pp. 28-44, 2006.
[48] A. Prencipe, "Technological competencies and product's evolutionary dynamics a case study from the aero-engine industry," Research Policy, vol. 25, no. 8, pp. 1261-1276, 1997.

[49] S. Nazli Wasti and J. K. Liker, "Collaborating with suppliers in product development: A U.S. and Japan comparative study," IEEE Transactions on Engineering Management, vol. 46, no. 4, pp. 444-461, 1999.

[50] F. E. A. van Echtelt, F. Wynstra, A. J. van Weele, and G. Duysters, "Managing supplier involvement in new product development: a multiple-case study," Journal of Product Innovation Management, vol. 25, no. 2, pp. 180-201, 2008.

[51] C. D. Ittner and D. F. Larcker, "Product development cycle time and organizational performance," Journal of Marketing Research, vol. 34, no. 1, pp. 13-23, 1997.

[52] D. Tanggapan, C. Geetha, R. Mohidin, and V. Vincent, "The relationship between economic growth and foreign direct investment in Malaysia: analysis based on location advantage theory," Management, vol. 1, pp. 24-31, 2011.

[53] G. L. Ragatz, R. B. Handfield, and T. V. Scannell, "Success factors for integrating suppliers into new product development," Journal of Product Innovation Management, vol. 14, no. 3, pp. 190-202, 1997.

[54] T. E. Johnsen, "Supplier involvement in new product development and innovation: taking stock and looking to the future," Journal of Purchasing and Supply Management, vol. 15, no. 3, pp. 187-197, 2009.

[55] S. Cheon and F. Liang, "Bayesian phylogeny analysis via stochastic approximation Monte Carlo," Molecular Phylogenetics and Evolution, vol. 53, no. 2, pp. 394-403, 2009.

[56] B. Mau, M. A. Newton, and B. Larget, "Bayesian phylogenetic inference via Markov chain Monte Carlo methods," Biometrics, vol. 55, no. 1, pp. 1-12, 1999.

[57] B. Rannala, "Identifiability of parameters in MCMC Bayesian inference of phylogeny," Systematic Biology, vol. 51, no. 5, pp. 754-760, 2002.

[58] A. Ansari, K. Jedidi, and S. Jagpal, "A hierarchical Bayesian methodology for treating heterogeneity in structural equation models," Marketing Science, vol. 19, no. 4, pp. 328-347, 2000.

[59] J. Arbuckle, Amos 18, Amos Development Corporation, Crawfordville, Fla, USA, 2009.

[60] X. Jiang and S. Mahadevan, "Bayesian structural equation modeling method for hierarchical model validation," Reliability Engineering and System Safety, vol. 94, no. 4, pp. 796-809, 2009.

[61] L. M. Birou and S. E. Fawcett, "Supplier involvement in integrated product development: a comparison of US and European practices," International Journal of Physical Distribution \& Logistics Management, vol. 24, pp. 4-14, 1994.

[62] J. C. Nunnally, Psychometric Theory, McGraw-Hill, 1978.

[63] B. W. Yap and K. W. Khong, "Examining the effects of customer service management (CSM) on perceived business performance via structural equation modelling," Applied Stochastic Models in Business and Industry, vol. 22, no. 5-6, pp. 587-605, 2006.

[64] E. G. Carmines and R. A. Zeller, Reliability and Validity Assessment, vol. 17, SAGE Publications, 1979.

[65] E. W. Anderson and C. Fornell, "Foundations of the American customer satisfaction index," Total Quality Management, vol. 11, no. 7, pp. S869-S882, 2000.

[66] J. F. Hair, R. E. Anderson, R. L. Tatham, and W. C. Black, Multivariate Data Analysis, Prentice Hall International, New York, NY, USA, 5th edition, 1998. 
[67] K. W. Khong, "Service quality index: a study on Malaysian banks," Contemporary Management Research, vol. 5, pp. 109124, 2009.

[68] B. Muthén and T. Asparouhov, "Bayesian SEM: a more flexible representation of substantive theory," Psychological Methods, vol. 17, no. 3, pp. 313-335, 2012.

[69] R. Grewal, J. A. Cote, and H. Baumgartner, "Multicollinearity and measurement error in structural equation models: implications for theory testing," Marketing Science, vol. 23, no. 4, pp. 519-629, 2004.

[70] C. Fornell and D. F. Larcker, "Evaluating structural equation models with unobservable variables and measurement error," Journal of Marketing Research, pp. 39-50, 1981.

[71] Y. S. Chen and C. H. Chang, "Greenwash and green trust: the mediation effects of green consumer confusion and green perceived risk," Journal of Business Ethics, pp. 1-12, 2012.

[72] L. Trygg, "Concurrent engineering practices in selected Swedish companies: a movement or an activity of the few?" The Journal of Product Innovation Management, vol. 10, no. 5, pp. 403-415, 1993.

[73] L.-E. Gadde and I. Snehota, "Making the most of supplier relationships," Industrial Marketing Management, vol. 29, no. 4, pp. 305-316, 2000.

[74] A. H. Rubenstein and J. E. Ettlie, "Innovation among suppliers to automobile manufacturers: an exploratory study of barriers and facilitators," R\&D Management, vol. 9, pp. 65-76, 1979.

[75] J. H. Heizer and B. Render, Operations Management, Pearson, England, UK, 10th edition, 2011.

[76] A. Das and R. Narasimhan, "Purchasing competence and its relationship with manufacturing performance," Journal of Supply Chain Management, vol. 36, pp. 17-28, 2000.

[77] J. L. Cavinato, "Fitting purchasing to the five stages of strategic management," European Journal of Purchasing and Supply Management, vol. 5, no. 2, pp. 75-83, 1999.

[78] J. Tidd, "Innovation management in context: environment, organization and performance," International Journal of Management Reviews, vol. 3, no. 3, pp. 169-183, 2001.

[79] F. Damanpour, "Organizational complexity and innovation: developing and testing multiple contingency models," Management Science, vol. 42, no. 5, pp. 693-716, 1996. 


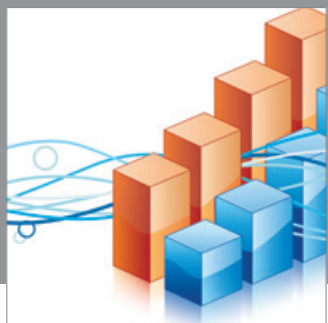

Advances in

Operations Research

mansans

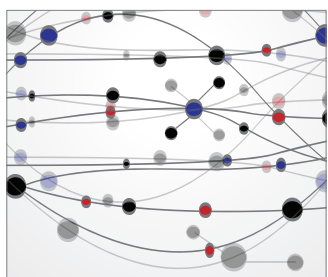

The Scientific World Journal
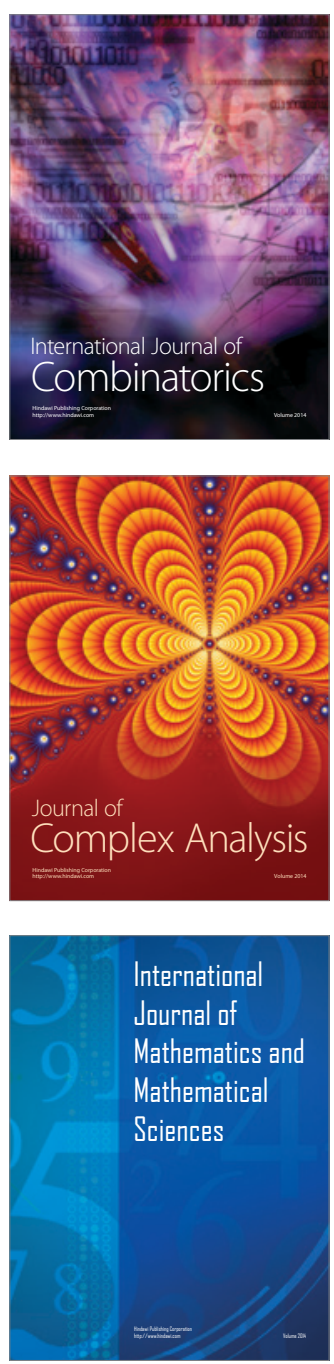
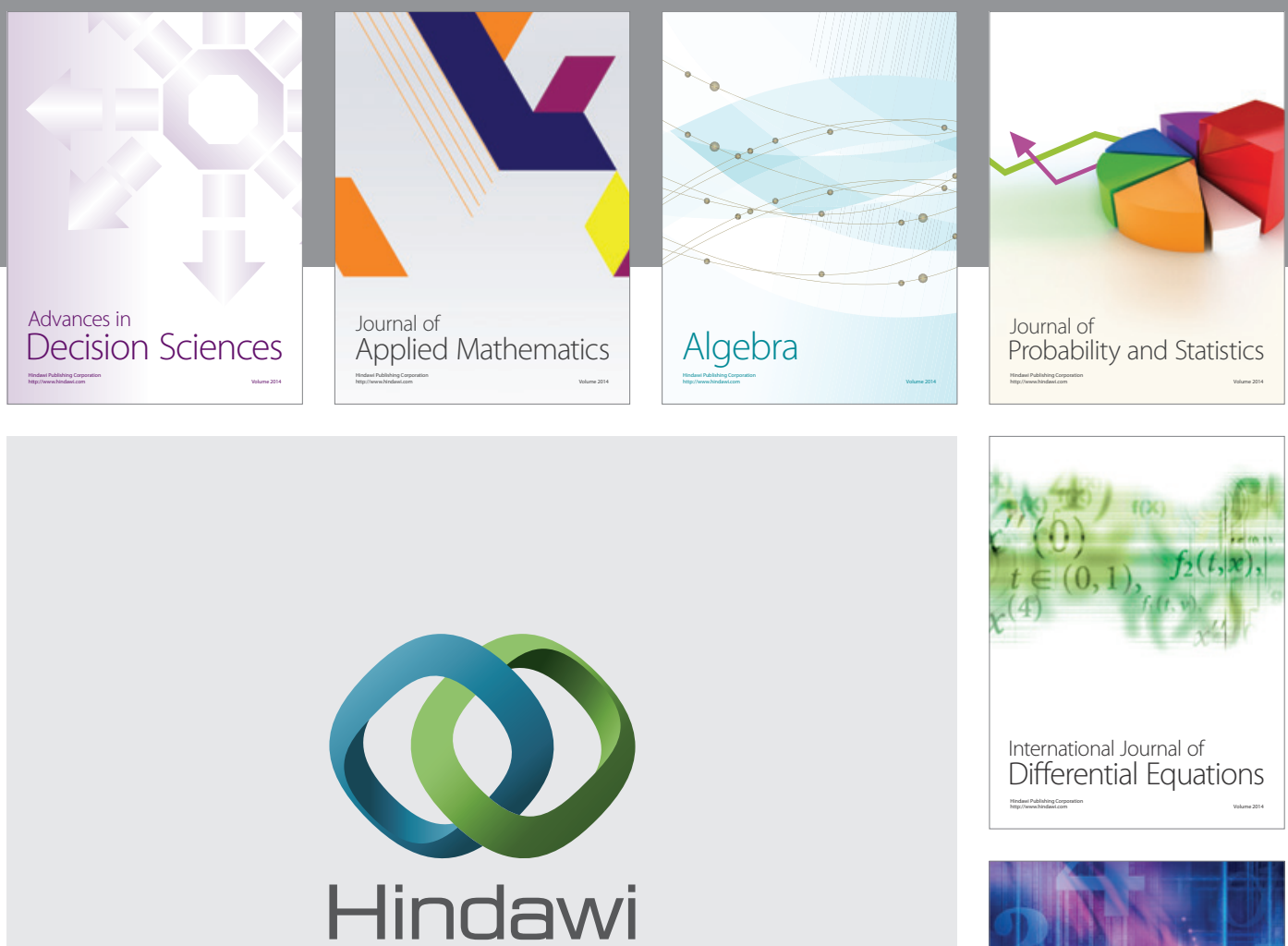

Submit your manuscripts at http://www.hindawi.com
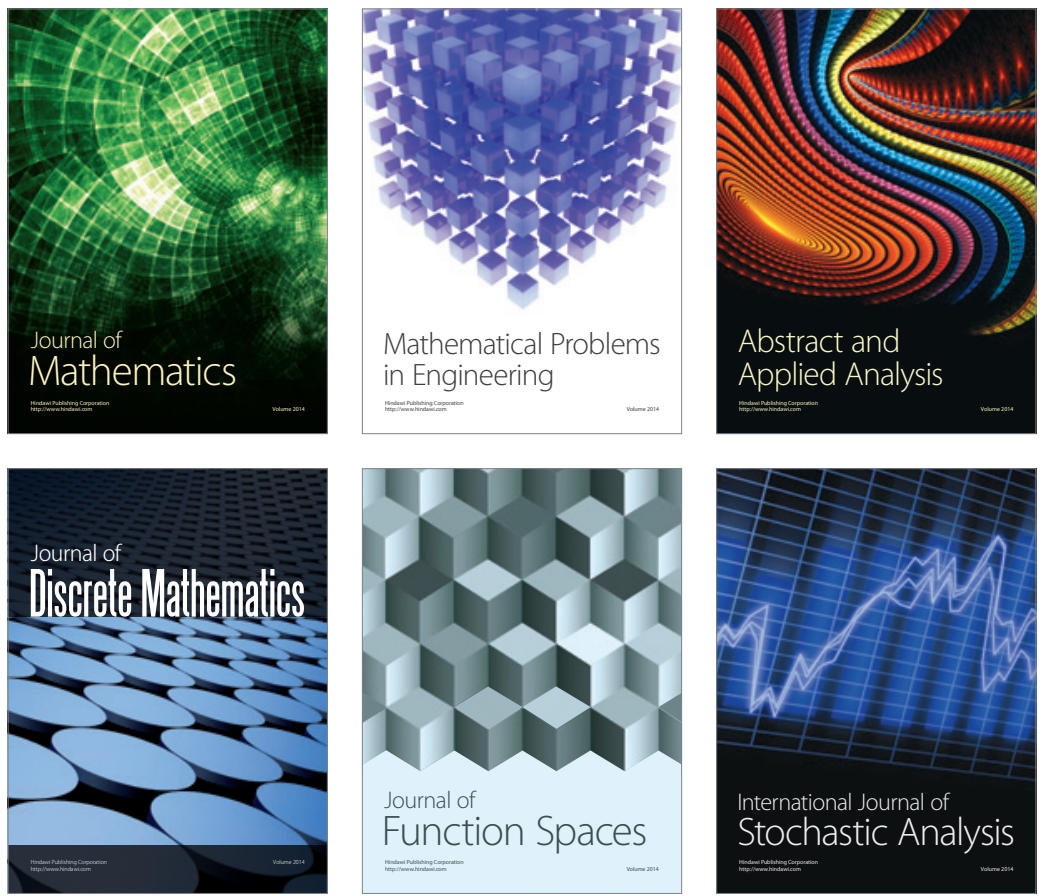

Journal of

Function Spaces

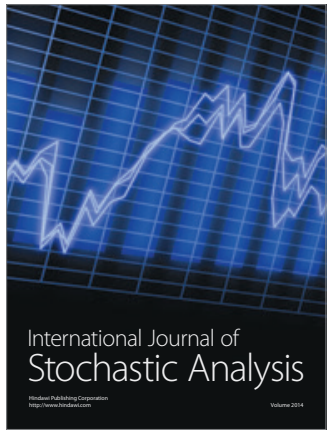

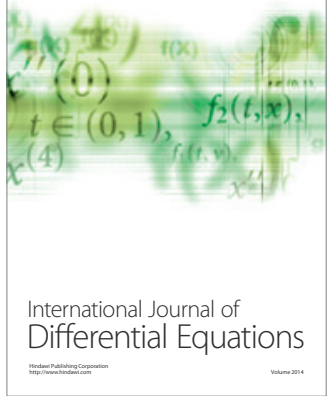
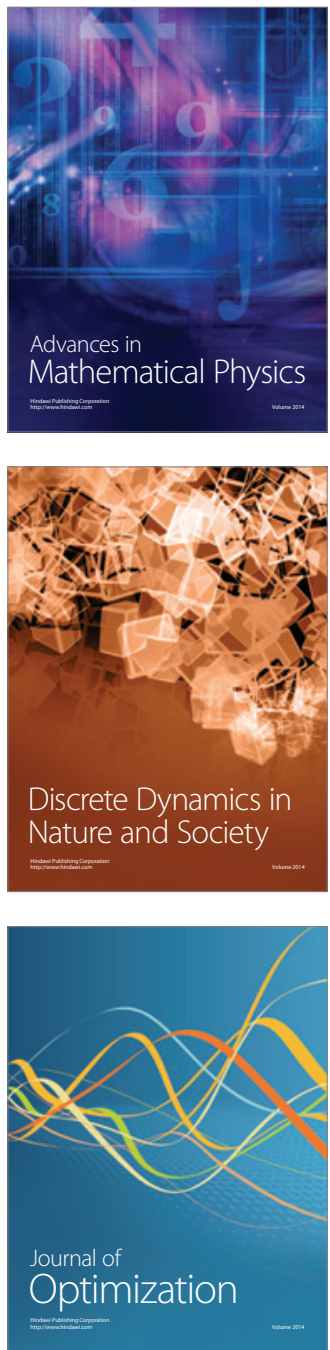